\title{
Enhancement of Individual and Community Competence: The Older Adult as Community Worker ${ }^{1}$
}

\author{
Margaret Gatz \\ University of Southern California
}

Oscar A. Barbarin

University of Michigan

Forrest B. Tyler

University of Maryland

Roger E. Mitchell

Social Ecology Laboratory, Stanford University

John A. Moran

St. Elizabeth's Hospital, Washington, D.C.

Philip J. Wirzbicki

West Central New Hampshire Community Mental Health Services, Hanover, New Hampshire

Janice Crawford and Annabel Engelman

Prince George's County Health Department, Cheverly, Maryland

This paper presents an evaluation of a primary prevention program designed to enhance individual and community competence in older adult community workers and in community residents with whom they worked. A total of 22 community workers and 97 community residents participated in the study; 30 residents constituted a posttest-only control group. Pre-post changes included increased knowledge of community services among all participants, as well as increased number of community information channels and increased life satisfaction for the workers. Residents, particularly black residents, became more internal, and

\footnotetext{
${ }^{1}$ This study was supported by DHEW Administration on Aging grant No. 90-A-520/01 and $90-A-520 / 02$, and by the University of Maryland Computer Sciences Center. We acknowledge Daniel Hurley's contribution to the project as Year 1 Field Coordinator. We thank Anne Bogat, Elissa Gease, Nancy Haws, Shari Miller, Cynthia Pearson, Carl M. Rogers, Richard Weisblatt, and the anonymous reviewers of the manuscript for their assistance. We also thank the community workers who helped to develop and conduct the project.
} 
their increased sense of personal control was related to their increased knowledge of services. Thus, the helper-therapy principle was supported for these older adult, mostly female, community workers, and their helping role had a net empowering effect.

In practice, primary prevention has often been synonymous with early intervention programs with young children (President's Commission on Mental Health, 1978). However, the focus of primary prevention on building coping skills, reducing the detrimental effects of social stressors, and counteracting sources of powerlessness seems especially suited to intervention with older adults as well (Albee, Note 1). Further, since the current cohort of aged are often reluctant to use services designated for mental or emotional problems, a preventive or educational approach might be more practicable (Gatz, Smyer, \& Lawton, 1980).

The primary prevention program described in this paper employed older adults as indigenous community workers who served as educators of other community-residing older adults. The goal of the program was to increase adaptive strengths of both the workers and the residents along two dimensions: their selfperceived competence as individuals and their level of competence within the community. Thus, the program reflects one particular conceptual approach to primary prevention. Following Cowen (1980), it was programmatic, intentional, and aimed at promoting health, and it had both direct and indirect targets.

Definitions of individual and community competence both shaped the intervention and determined the measures used for evaluation. Individual competence was defined in terms of three developmentally derived facets: (a) a sense of self-efficacy, or being an active agent in control of one's life; (b) a worldattitude that includes hope and interpersonal trust; and (c) relevant behavioral attributes, for example, problem-solving skills (Smith, 1968; Tyler, 1978). The intervention was designed to strengthen all three facets.

Our definition of community competence was influenced by Iscoe (1974), who described people in a competent community as having alternatives and as knowing how to obtain and use resources, thereby counteracting feelings of powerlessness. A systems model of people's competence in their communities, proposed by Hurley, Barbarin, and Mitchell (1981), emphasized the community processes of resource utilization and problem solving, as well as communication and influence/power channels. These processes were embodied in the intervention approach.

In developing the community worker role, we drew on concepts such as natural helpers and indigenous paraprofessionals (Gershon \& Biller, 1977; Mitchell \& Hurley, 1981). The rationale for their use has included: the special skills and understanding that derive from being indigenous, particularly the ability to reach people not ordinarily in touch with mental health channels; and the potential of strengthening and creating resource networks in the commu- 
nity. Older adults have not often been used as paraprofessionals. Yet, Neugarten's (1975) analysis of the role of the "young-old" in this society suggests that people in this age group, especially women, are well suited for community work because they are interested and able to become social contributors. Moreover, nonprofessionals reap personal benefits from working as helpers (Riessman, 1965), an aspect particularly emphasized in discussions of older adult nonprofessionals (cf. Faulkner, 1975).

We tried to develop a community worker role that would benefit both helpers and helpees. The research reported in this paper evaluates how well the program achieved its goals. We hypothesized that the program would increase the competence of both the community workers and the residents with whom they worked, and that increased competence would be demonstrated by gains in sense of self-efficacy, interpersonal trust, problem-solving skills, and access to community resources. Further, we hypothesized that changes in community and individual competence should be related, particularly that increased knowlege and use of community resources should relate to increased sense of personal control.

\section{METHODS}

This paper focuses on the first year of a 2-year project. For Year 1, preand posttest individual and community competence data were collected and a posttest-only control group was used. Supplemental pre- and posttest individual competence data from Year 2 are presented. Records of the intervention process were kept over both years.

\section{Participants}

The project was carried out in 20 towns, 10 towns in each of two suburban mental health catchment areas. According to the 1970 census data, Area A was $67.6 \%$ black and Area B was $90.5 \%$ Anglo. Median income in each area was just over $\$ 9,000$. Both areas were characterized by high mobility, with high-risk groups including aged persons living alone (up to $13.3 \%$ of households in one census tract) or in poverty (up to $80 \%$ of all aged in one tract).

Workers. Twenty-two people (10 Anglo, 11 black, 1 Hispanic; 18 female, 4 male) aged 50 or older $(M=63)$, were employed as community workers. We recruited individuals who were (a) long-term community residents, (b) active in individual and community problem-solving as evidenced by their participation in work, volunteer activities, and civic affairs, and (c) knowledgeable about their community and its resources. These criteria guided what was largely a self-selection process (cf. McGee, 1974). Project personnel described the com- 
munity worker role to Senior Citizens' clubs and to other community groups. Individual nominees and self-nominees were interviewed both to describe the role further and to assess their interest. Finally, groups of six to eight potential workers were invited to participate in 2-day worshops. Everyone who attended the workshops continued with the project. By the end of the second year, eight workers had dropped out of the project, most for health-related reasons. Due to dropout, lag time at the start of the project, and missing data, Year 1 individual competence data were analyzed for 19 workers; and Year 1 community competence data for 14 .

The 2-day workshops at the beginning of the program were designed to explain the project more fully to the workers, to give them experience in the tasks that they would be doing, and to build on their knowledge and skills. Topics included interviewing and active listening, problem solving, using formal and informal community resources, and administering the evaluation measures. Thereafter, workers spent 8 or more hours a week in project activities and attended weekly meetings to review cases, share information and assistance, continue to improve skills, and exchange support. Workers were paid for all time spent on the project.

Year 1 Residents. Workers had contact with three categories of residents: those selected at random, older adults referred (or self-referred) to workers for particular problems, and residents selected for contact by the workers. This third group included people deemed pivotal in informal networks as well as people whom the workers felt could use some assistance. To generate the random sample, a list of households was produced for each town using a table of random numbers first to select blocks and then homes on those blocks. Over 800 residents were surveyed (Barbarin, 1977).

The present evaluation focuses on subsets of 78 residents who completed both pre and post community-competence measures and 21 who completed pre and post individual-competence measures. Of the 78,37 were from the random sample. Comparisons between random and nonrandom residents indicated that the groups could be combined. The residents were comparable to the workers in age, race, and sex.

Presentations made by project personnel to recruit workers were also the first step in publicizing the project to potential users. Community workers met with representatives of mental health and human service agencies and made presentations to other community groups. Each interaction with a resident was recorded by the worker on a contact sheet. Over the 2 years, contact sheets were completed for 73 residents who reported one or more specific problems. Residents categorized as referrals and self-referrals, most of whom were older adults living alone, heard about the project either from relatives, friends, and neighbors (39.4\%); civic associations, church groups, etc. (18.2\%); human service agencies (36.4\%); or information and referral services (6.1\%). In $38.4 \%$ of the cases, the contact was by a person who was seeking the worker's assis- 
tance in helping a third person. For example, the manager of a subsidized senior citizen apartment building might call about a building resident. The number of contacts per resident ranged from 1 to 24 , averaging just over 3 .

Control Group Residents. At the time of the Year 1 posttest, a new random sample of 30 residents was generated, and community-competence measures were collected for that group, i.e., a posttest-only control group. Obtaining the community competence data was itself part of the intervention; therefore, a pre-post control group was precluded because it would be equivalent to an experimental group who had one contact with a worker.

Year 2 Residents. For Year 2, a new group of 18 residents completed pre and post individual-competence measures.

\section{Measures}

Individual Competence. These self-report measures assessed the three facets of competence in Tyler's (1978) model, as well as perceived well-being or life satisfaction:

1. Self-efficacy, or locus of control, was assessed by the Rotter I-E Scale (Rotter, 1966), which includes 23 forced-choice items scored for externality. The following is a typical item: "A. Becoming a success is a matter of hard work; luck has little or nothing to do with it." vs. "B. Getting a job depends mainly on being in the right place at the right time."

2. Interpersonal trust was assessed by the Rotter Trust Scale (Rotter, 1967), which includes 24 statements rated on 5-point Likert-type scales; e.g., "Most people can be counted on to do what they say they will do."

3. Active planful problem-solving was assessed by the Behavioral Attributes of Psychosocial Competence (BAPC) Scale (Tyler, 1978), which consists of 58 forced-choice items. A typical item is as follows: "A. When I'm involved in something and begin to have setbacks, I may drop it unless it really matters to me to finish it." vs. "B. When I take on something, I stick with it until it's finished."

4. Life satisfaction was assessed by the Life Satisfaction Index A (Neugarten, Havighurst, \& Tobin, 1961), which includes 20 agree/disagree items; e.g., "I've gotten pretty much what I expected out of life."

For Year 2, the test battery was shortened by identifying items that contributed little to total test scores. The trust scale was shortened from 24 to 18 items; and life satisfaction, from 20 to 15 . Correlations between the full and abbreviated scales ranged from .93 to .98 .

Community Competence. A community survey based on Hurley et al.'s (1981) model of community competence assessed attitudes, knowledge, and self-reported behavior with respect to community resources:

1. To assess community strengths and needs, the number of strengths and needs listed by participants in response to open-ended questions were used 
as scores. Examples of strengths were quietness, friendliness, and convenience; example of deficits were lack of services, substandard housing, and crime. In addition, participants rated on 7-point scales both their satisfaction with their community and the severity of 13 different needs (e.g., transportation, upkeep of homes and property, services for senior citizens). An average need rating was computed from these responses.

2. To assess knowledge and use of community service institutions, participants were asked the following yes/no questions about five agencies: (a) Do you know what services it offers? (b) Do you know where it is? (c) Do you know someone who works there? (d) Do you use its services? The total number of "yes" responses was used as an index. Participants who had used a given service rated the quality of its performance on a 4-point scale.

3. To assess problem-solving, four hypothetical community problems related to mental health, consumer, tax, and transportation issues were described (e.g., an elderly neighbor's electricity was cut off because of nonpayment). Participants were asked what different things they might do about each of the four situations. Both mean number of alternative solutions and mean activeness of involvement in problem-solving were used as scores. Responses were rated as separate alternatives when they involved separate activities or resources, such as talking to the person, taking up a collection, calling the Department of Social Services, sending the person to a minister. Activeness was coded on a 4point scale from 1 = passive-nonactive to $4=$ direct-active help-giving.

4. To assess number of information channels, participants listed their sources of information about community services, both formal and informal, and the total number of channels named was used as a score. Examples of information channels were relatives, friends, newspapers, television, town meetings.

\section{Procedure}

Research and service aspects built upon one another. In the community competence survey, workers asked whether the residents knew about various community services and how they would solve hypothetical problems. At the same time, workers provided residents with a resource directory of agencies and services and made themselves available to help with personal or community problems. Workers were trained both to model active problem-solving and to try to help people to help themselves. Contact sheet data reported in the Results section below describe the intervention in more detail.

\section{RESULTS}

The results are presented in four parts: contact sheets, community-competence measures, individual-competence measures, and the relationship between individual and community competence. 


\section{Contact Sheets}

These data describe the intervention process, including kinds of problems presented to the workers, resources used in problem-solving, and types of helping approaches used by the workers.

Of the problems presented to the workers, $76.7 \%$ were service-related. The single greatest difficulty reported was transportation. Others included housing, clothing, food stamps, and medicaid. The problem often was related to a lack of information about, for example, eligibility requirements and application procedures. Physical problems accounted for $15.5 \%$ of the contacts. They ranged from needing a hospital bed, to house repair, to wanting a stoplight at a busy intersection. People-related problems accounted for $8.2 \%$ of the contacts. They involved such things as loneliness, alcoholism, and caring for an aged parent.

Before the present workers got involved with such problems, residents had tried, on the average, less than one community resource. During the problemsolving process, workers generated an average of 1.50 alternatives; and residents, .75. Resources were coded as "formal systems" (e.g., Department of Social Services, Health Department, housing authority, local government), "local" (e.g., church groups such as the Ladies of Charity, civic associations) or "informal" (relatives, friends, neighbors). Residents used and suggested the three types of resources with about equal frequency. Workers tended to turn first to local resources while seeking more permanent solutions via formal systems resources. For example, a church group might offer temporary help while application was being made to DSS for food stamps.

The contact sheet identified various helping activities in which the comumunity worker engaged. On the first contact, $65.2 \%$ of the time the worker gave the resident information from the resource directory, and $55.7 \%$ of the time the worker put the resident in touch with formal or local helping networks. Across a series of contacts for each case, the primary service-related strategies included the worker's making a call to an agency $(43.1 \%)$, the workers arranging for the resident to call an agency (20.8\%), and the worker's taking the resident to an agency (15.3\%). Another $12.5 \%$ of the time, the only intervention was talking with the resident. Thus, both formal and informal channels were used, and workers maintained a balance between active and educational.strategies.

\section{Community Competence}

Mean scores for Year 1 are presented in Table I. Matched $t$ tests and $\chi^{2}$ tests for yes/no categorical data were used to evaluate overall change from preto posttest, with workers and residents combined. To test for differential change on the part of the workers as compared to the residents, $t$ tests for independent groups were used, where the dependent variables were pre-post difference scores. Finally, $t$ tests for independent groups, where the dependent variables 


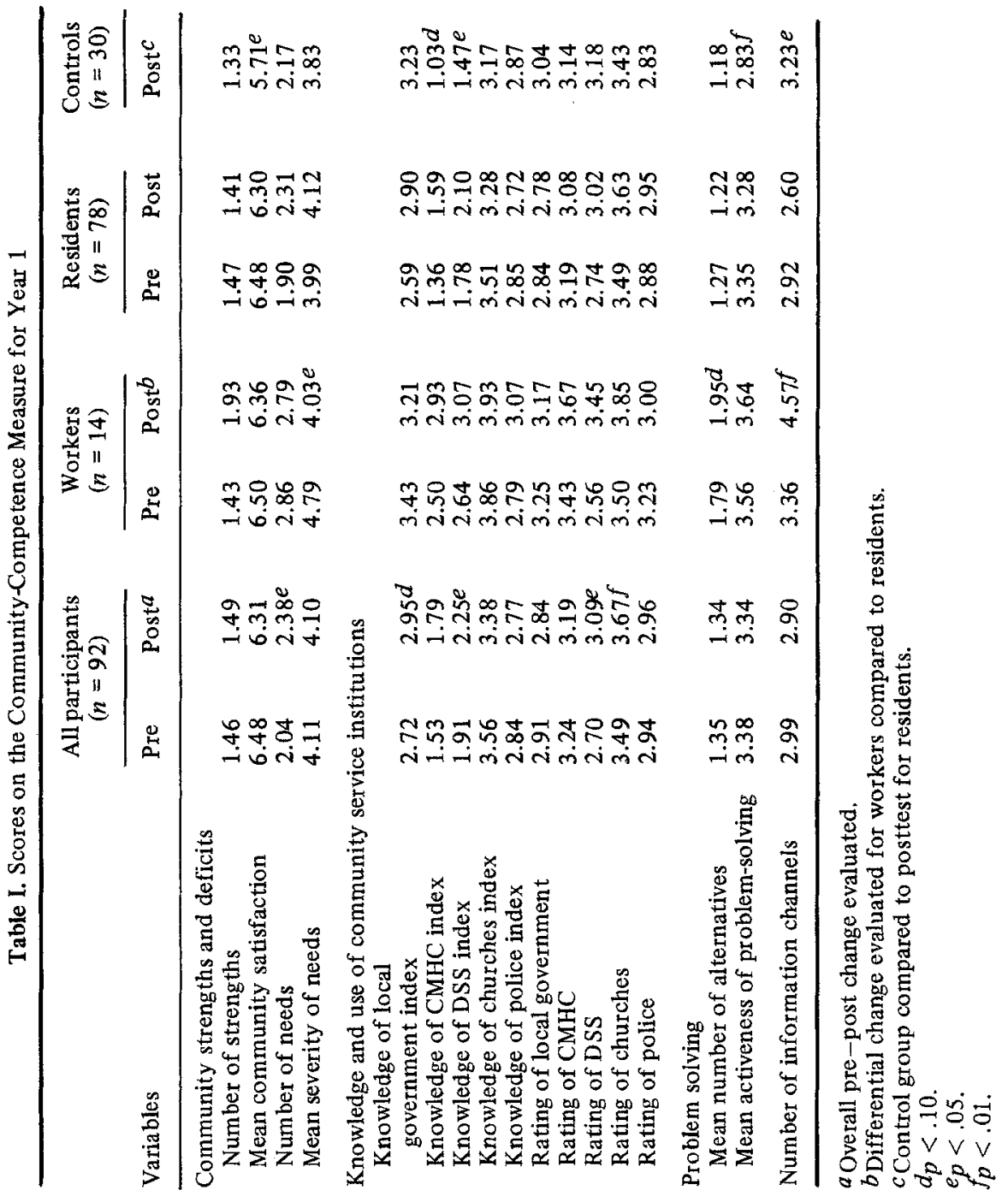


were posttest scores, were used to compare the residents and controls. The coupling of intervention and evaluation in a field setting led to diverse missing data and precluded multivariate analysis of variance.

Overall. Across all participants, there was little change in ratings of community satisfaction, due in part to initial ceiling effects. Participants, especially residents, became more sensitized to community needs, reporting significantly more needs at posttest than at pretest, $t(91)=2.53, p<.01$. Deficits mentioned frequently included lack of involvement in town activities, absentee landlords, church attendance.

The total participant group increased in its knowledge and use of community services. The summed index for the Department of Social Services increased significantly, $t(91)=2.29, p<.05$. The $\chi^{2}$ analyses of the separate questions about knowledge and use indicated significant increases in knowledge of where DSS was located and in use of services offered by the town government. Finally, participants rated DSS and their local churches significantly more positively at posttest than at pretest.

Differential Change. On the ratings of community needs, at posttest the residents' ratings of the severity of the needs had increased, while the workers' ratings indicated decreased severity, $t(90)=2.32, p<.05$. Needs for which this pattern was significant included keeping up houses and property, and emergency home services and transportation for the sick and elderly.

In comparison to the residents, the workers increased significantly in their number of information channels, $t(90)=3.20, p<.01$, and they tended also to increase in the number of alternative problem solutions that they generated, $t(90)=1.73, p<.10$.

Control Group. Significant differences between residents and controls were found on four variables. Residents at posttest were significantly higher than controls on knowledge and use of DSS, $t(106)=2.17, p<.05$. On this variable, pre-post comparisons had also shown significant gain for participants. Residents at posttest were also significantly higher than controls on community satisfaction, $t(106)=2.22, p<.05$, and activeness of problem-solving, $t(106)=5.55$, $p<.01$. On these two variables, however, it was also the case that residents at pretest were significantly higher than controls, and pre-post comparisons had not shown significant change for participants. Finally, contrary to expectation, controls were significantly higher than residents at posttest on number of information channels, $t(106)=-2.10, p<.05$.

\section{Individual Competence}

Mean scores are presented in Table II. Data from Year 1 and Year 2 residents were comparable when tested separately by race; therefore, residents' data from both years were combined. Matched $t$ tests were used to evaluate overall 
Table II. Mean Scores on the Individual-Competence Measures

\begin{tabular}{|c|c|c|c|c|c|c|}
\hline \multirow[b]{2}{*}{ Variables } & \multicolumn{2}{|c|}{$\begin{array}{l}\text { Workers } a \\
(n=19)\end{array}$} & \multicolumn{2}{|c|}{$\begin{array}{l}\text { Year } 1 \text { residents } \\
\quad(n=21)\end{array}$} & \multicolumn{2}{|c|}{$\begin{array}{c}\text { Year } 2 \text { residents } \\
\quad(n=18)\end{array}$} \\
\hline & Pre & Post & Pre & Post & Pre & Post \\
\hline Rotter I-E $b$ & 9.10 & 9.68 & 11.24 & 9.40 & 9.38 & 8.77 \\
\hline $\begin{array}{l}\text { Behavioral attributes } \\
\text { of psychosocial } \\
\text { competence }\end{array}$ & 33.61 & 34.63 & 31.57 & 32.25 & 32.25 & 31.56 \\
\hline Trust $c$ & $\begin{array}{c}67.78 \\
(51.45)\end{array}$ & $\begin{array}{c}66.16 \\
(48.90)\end{array}$ & $\begin{array}{c}65.86 \\
(48.52)\end{array}$ & $\begin{array}{c}65.71 \\
(47.95)\end{array}$ & 47.76 & 47.83 \\
\hline Life satisfaction $c$ & $\begin{array}{l}12.53 \\
(9.41)\end{array}$ & $\begin{array}{c}14.00 \\
(11.05)\end{array}$ & $\begin{array}{c}13.57 \\
(10.29)\end{array}$ & $\begin{array}{c}13.43 \\
(10.21)\end{array}$ & 8.41 & 9.24 \\
\hline
\end{tabular}

$a$ Year 1 data only.

$b$ Scored for externality.

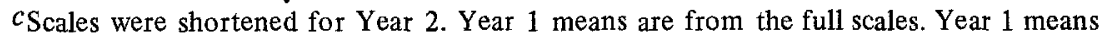
in parentheses are summed from the shortened item set, to be comparable to the Year 2 means.

change from pre- to posttest, with workers and residents combined. Differential change was evaluated using two-way analysis of covariance. One independent variable was workers vs. residents; the other was race. The dependent variable was posttest scores with pretest scores as covariates.

Overall. The total participant group increased in life satisfaction, $t(53)=$ $2.21, p<.05$, with the gain attributable particularly to the workers.

Differential Change. On the Rotter I-E Scale, a significant Group $\times$ Race interaction, $F(1,48)=3.92, p<.05$, showed that black residents became more internal on locus of control, while other participants changed less or became more external.

\section{Relationship Between Individual Competence and Community Competence}

The significant change on locus of control for residents permitted an exploratory test of whether increased internality, one measure of individual competence, related to increased knowledge about community resources. Accordingly, we calculated two new variables, the first of which was a locus of control difference score, with positive values indicating increased internality and negative values indicating increased externality. The knowledge variable was calculated from summed indices for knowledge and use of local government, the Community Mental Health Center, and the Department of Social Services. A positive difference score indicated increased knowledge and use of community resources. 
The Pearson correlation between these two variables was significant $r(12)=.51$, $p<.05$, indicating that gain in internal control related to increase in information about community resources.

\section{DISCUSSION}

The goal of the project was to develop a "before-the-fact" program (Cowen, 1980) to promote competence in older adults, by enhancing both their individual self-attributions and their integration in their communities, and by influencing both community workers and community residents. To what extent was the program sufficiently successful to warrant further development and research?

The data showed helper effects. Workers felt more satisfied with their lives; and they learned more about community resources and support networks, as indicated by their increased knowledge of community services and number of channels by which to obtain community information. We also observed that many workers used their affiliation with the project in seeking to increase services to the aged in their communities. Moreover, workers' comments attested directly to helper effects e.g.:

I got a lot out of the project personally, I didn't realize that all these resources were available or that so many people needed them. The project has been an asset to me too... I've learned how to break down some of my own problems so I can do something about them.

These changes reflect a combination of the effects of (a) information and support provided by the training sessions and weekly meetings, (b) experience and knowledge gained from actually helping residents with their problems, and (c) the role itself. The results substantiate the applicability of the helper therapy principle (Riessman, 1965) for this group of "young-old" women.

It was important that the program not simply benefit the helpers but that it alsocontribute to the community. Its main effects on the community residents, or helpees, were to improve their knowledge of community services and, in a correlated way, to increase their sense of personal control. These results are consistent with Iscoe's (1974) view that there are ties between community competence and sense of power. They also lend support to prevention programs that (a) educate community residents about services and (b) build links to services and to informal resources.

Gain in internality was greatest for black residents. Mitchell, Barbarin, and Hurley (1981), using the same community competence survey to compare a black and a white town, found that black community members saw greater service-related deficits and relied more on "informal" and "local" than on "formal" resources. Perphaps improved knowledge of how to obtain formal services is a particularly useful intervention for black residents, and therefore one that helps to strengthen their sense of control. 
What seem to be the mechanisms by which the program achieved its effects? The process data from the contact sheets as well as the outcome data suggest that one important mechanism was community education - providing information about services and about how specifically to access those services. A second mechanism - though both contact sheet and outcome data suggest that it was less frequent - was teaching and modeling problem-solving skills. The third mechanism, reflecting the locus of control findings, was empowerment (Rappaport, 1981). One aspect of empowerment is information. A related aspect is attitudinal. The program assumed that the community workers were competent, i.e., resourceful active agents. That view was successfully incorporated into their role, as indicated by comments by one of the workers:

I try to show others how to be by how I treat them ... People in the civic association seem to look down on people, they want to do things for them and feel important.

Several of the study's methodological limitations should be noted. The number of participants was small. The measures were self-report. The integration of the evaluation into the intervention program made it difficult to define a control group. Although results from the new random sample assessed at posttest confirmed that participants had increased in knowledge of community services, they also suggested additional group differences that may have been due to sampling rather than to effects of the intervention.

Finally, several dilemmas associated with this type of program can be raised. In a similar program he conducted, Blonsky (1974) identified as a problem the conflict experienced by his workers between providing direct services and emphasizing community organization. This may be an especially difficult dilemma in programs designed to help older adults. Many older adults both want and need direct supportive services in order to continue to live independently. The dilemma is how to meet these needs in a way that preserves their choices and enhances their self-respect. Our data suggest that workers acted in ways that increased residents' sense of control, i.e., did not encourage an "unheal thy" dependency. On the other hand, the results offer only minimal evidence that the workers taught the residents the kinds of specific problem-solving skills that would enable them later to do more things for themselves.

This project also raised a second dilemma. Community workers were selected because they were key persons in natural helping networks in their communities. Their participation in the project legitimized and empowered them. The concern is the extent to which new resource networks created by this process may render an initially natural network "unnatural." The hope is that by using a collaborative approach with the workers, such an outcome can be averted.

As the above discussion indicates, the present study should be regarded as suggestive rather than conclusive. The findings argue for further use and evaluation of this approach in community settings, as one type of primary prevention program in mental health. 


\section{REFERENCE NOTE}

1. Albee, G. W. Primary prevention and aging: Sources of powerlessness. Invited address presented at the annual meeting of the American Psychological Association, Montreal, Canada, September 1980.

\section{REFERENCES}

Barbarin, O. A. Enhancing community competence: A model for community intervention. Joumal of Black Psychology, 1977, 4, 144-160.

Blonsky, L. E. Problems in the development of a community action program for the elderly. Gerontologist, 1974, 14, 394-401.

Cowen, E. L. The wooing of primary prevention. American Journal of Community Psycho$\log y, 1980,8,258-284$.

Faulkner, A. O. The black aged as good neighbors: An experiment in volunteer service. Gerontologist, 1975, 15, 554-559.

Gatz, M., Smyer, M. A., \& Lawton, M. P. The mental health system and the older adult. In L. W. Poon (Ed.), Aging in the 1980s: Psychological issues. Washington, D.C.: American Psychological Association, 1980.

Gershon, M., \& Biller, H. B. The other helpers. Lexington, Mass.: D.C. Heath, 1977.

Hurley, D., Barbarin, O., \& Mitchell, R. An empirical assessment of racism in community functioning. In O. Barbarin, P. Good, M. Pharr, \& J. Suskind (Eds.), Institutional racism and community competence. Rockville, Md.: National Institute of Mental Health, 1981.

Iscoe, I. Community psychology and the competent community. American Psychologist, $1974,29,607-613$.

McGee, R. K. Crisis intervention in the community. Baltimore: University Park Press, 1974.

Mitchell, R. E., Barbarin, O. A., \& Hurley, D. J. Problem-solving, resource utilization and community involvement in a Black and White community. American Joumal of Community Psychology, 1981, 9, 233-246.

Mitchell, R. E., \& Hurley, D. J. Collaboration with natural helping networks: lessons learned from studying paraprofessionals. In B. H. Gottlieb (Ed.), Social networks and social support. Beverly Hills: Sage Publications, 1981.

Neugarten, B. L. The future and the young-old. Gerontologist, 1975, 15, 4-9.

Neugarten, B. L., Havighurst, R. J., \& Tobin, S. S. The measurement of life satisfaction. Journal of Gerontology, 1961, 16, 134-143.

President's Commission on Mental Health. Report to the President of the President's Commision on Mental Health. Washington, D.C.: Government Printing Office, 1978.

Rappaport, J. In praise of paradox: A social policy of empowerment over prevention. American Journal of Community Psychology, 1981, 9, 1-26.

Riessman, F. The helper therapy principle. Social Work, 1965, 10, 27-32.

Rotter, J. B. Generalized expectancies for interval versus external control of reinforcement. Psychological Monographs, 1966,80(1, Whole No. 609).

Rotter, J. B. A new scale of measurement of interpersonal trust. Journal of Personality, $1967,5,651-665$.

Smith, M. B. Competence and socialization. In J. A. Clausen (Ed.), Socialization and Society. Boston: Little, Brown, 1968.

Tyler, F. B. Individual psychosocial competence: A personality configuration. Educational and Psychological Measurement, 1978, 38, 309-323. 